\title{
Iterative Factors Favoring Collaboration for Interorganizational Resilience: The Case of the Greater Montréal Transportation Infrastructure
}

\author{
Marie-Christine Therrien • Stéphane Beauregard • \\ Anais Valiquette-L'Heureux
}

Published online: 3 March 2015

(c) The Author(s) 2015. This article is published with open access at Springerlink.com

\begin{abstract}
Between members of a network, interorganizational resilience is favored by effective collaboration and coordination during a crisis. The quality of that collaboration depends on various iterative factors present between these organizations before the occurrence of a crisis. We find that these factors are iterative since collaboration factors follow a mutually reinforcing cycle: collaboration within a crisis management network is conditioned by a general agreement, which is in turn conditioned by the extent to which the institutions coordinate themselves prior to crisis. We evaluated the factors that promote collaboration between public and private organizations that manage the Greater Montréal transportation infrastructure. These factors are based on adaptive management processes such as mutual agreements, common organizational culture, knowledge and financial resources, levers of power, regulations, and pressure. Crisis management coordination represents the ability to build and assess the effectiveness of common response plans to risks to which they are exposed. We show how these processes vary depending on the links between private and public organizations.
\end{abstract}

Keywords Adaptive management - Collaborative management · Interorganizational resilience $\cdot$ Montréal $\cdot$ Transportation infrastructure

M.-C. Therrien $(\square) \cdot$ A. Valiquette-L'Heureux

National School of Public Administration (ENAP), Montréal, QC H2T 3E5, Canada

e-mail: mctherrien@enap.ca

S. Beauregard

University of Montréal, Montréal, QC H3T 1J4, Canada

\section{Introduction}

To respond to complex events involving more than one organization, and to mitigate deficiencies in collective management that arose during previous crises, Wise (2006) advocates "adaptive management." This management model improves the resilience of a network by facilitating coordination between different entities operating in the same particular context, although pursuing objectives that are both common and independent. Adaptive management is underpinned by the need to bring together the actors concerned with a problem to ensure collaboration in action. This collaboration is sustained by the systematic sharing of information possessed by each stakeholder, and by the pooling of their objectives. It is only through collective analysis of information that joint decisions can be made to reduce efficiently the consequences of a situation. Following this sharing, the actors can implement concerted action plans. Direct and indirect impacts from this decision making can then be analyzed in real time with a scientific approach. The decision-makers can consequently adapt their decisions to the changing environment. Adaptive management promotes organizational learning, while it puts the scientific data gathered to optimal use. It also grants the flexibility that managers require to adapt their actions as new information becomes available. Decisions are thus seen as learning opportunities because they are based on incomplete information that should be constantly enriched. Adaptive management is thus an active, continuous process.

Adaptive management begins by bringing together the interested parties to discuss the problem and exchange the available data. The decision-makers can then develop models or action plans to solve the problem (Johnson 1999). Therefore the first objective of coordination 
between organizations that want to respond to a common problem or crisis consists of identifying the members of the network affected by the event and jointly defining the scope of the problem. During a crisis, the need for coordination between the parties concerned increases, but the need to coordinate is not uniquely related to solving a common problem (Gray 1985). Coordination must originate from a common approach upstream of a particular situation and is rooted in a collaboration process.

The quality of this collaboration is notably conditioned by factors that encourage this relation (Alexander 1993). Collaboration between organizations will attain specific objectives only if the various stakeholders involved agree on the nature of this relation, and on the roles and responsibilities of each actor. The legitimacy of all the participants in a common process also strongly influences the quality of the relation among the organizations (Gray 1985; Klijn 2008). Before coordinating to solve a problem, the actors concerned must consider that the collaboration will have beneficial effects on their organization such that the relation generates the anticipated results (Schermerhorn 1975).

Moreover, number of participants, mixed motives, freeriding, and other contextual and institutional pressures among other factors tamper the willingness and ability for adaptive efficiency in an open collaboration context (Lotia and Hardy 2008). Particularly in the context of crisis, there is ground for opportunistic behavior (Gilbert 2003). In Benson's (1975) theory of interorganizational networks, organizations' powers vary according to internal network structure and external ties, that is, external social linkages embedded in larger "societal dominance" patterns. Interaction, according to Benson, is therefore always oriented towards "the fulfillment of program requirements [...] the maintenance of a clear domain of high social importance [...] the maintenance of orderly, reliable pattern of resource flow [...or] the extended application and defense of the agency's paradigm" (Benson 1975, pp. 232-233).

These empirically-grounded insights prove that in analyzing complex systems, whose boundaries are blurred by the complexity of the issues requiring collaborative management, it cannot be presumed that linkages in networks are exempt from power bargains and other mechanisms of self-defence and self-promotion. Therefore, coordination between organizations is enabled by various incentive or coercive factors, internal or contextual to the communication, decisional process (Alexander 1993; De Bruijne et al. 2010). We begin by presenting our findings on the main incentives that favor coordination between the members of the network of managers of transport critical infrastructures of Greater Montréal, and identify the key differences between public and private organizations of the same network. Next we explain the empirical background of this case study. Then we introduce the methodology used to evaluate organizational models and explore the iterative factors that promote collaboration in an emergency situation. We then present our findings and show how mutual agreement on the objectives of the relation, a common culture, access to physical, human and information resources, levers of power and regulations, and various pressures and sanctions can positively or negatively influence collaboration between organizations. The article concludes by proposing avenues that emerge from the results obtained.

\section{Research Empirical Background}

The critical infrastructure (CI) systems of Québec have been scarcely studied in the past twenty years (Québec 1994, 1999; Therrien 2010; Tremblay 2010). After the ice storm crisis of 1998, the meteorological services were added to Canada's classification of CI. The domino effect that resulted from the storm-power outages disrupt the banking system and threaten water safety, health facilities, and other essential supplies_-made it clear that essential infrastructures where at risk. More than one in three households was without power or heat during prolonged periods in the cold of Québec's winter. All critical infrastructure network members were mobilized and made aware of their common vulnerability to such wide-ranging disruptions, tight coupling, and mutual interdependency. In Québec following an analysis of this 1998 event, 12 resilience sectors were created by the government to overview risks and conduct crisis coordination planning efforts (Québec 2009).

As noted by Lindsay (2014), legislation declaring a state of emergency granted the federal authority varying extraordinary powers for emergency response purposes, but the legislative acts grant few powers over or responsibility for the reduction of risks. The governments of Québec and Canada, as well as the municipal authorities, share jurisdiction over the threats that could affect one or several of the critical infrastructures. Moreover, the public and private sectors are conjointly responsible to maintain CI integrity or reinstall CI capacity after times of failure (Tremblay 2010). Since the September 11 attacks in the United States, national security policies have targeted five strategic intervention sectors with respect to potential threats of disruption within Canada: transport, health emergencies, border security, international security, and emergency operation and planning as well as intelligence (Godbout 2008).

Past research findings have described some of the features of the transportation network as critical infrastructure in Québec, more precisely, the Greater Montréal 
metropolitan region. Based on a 209 respondents survey, we determined that the transport network was viewed positively by respondents despite having a reputation for being riven by power struggles between system components. This positive image derived from the ability of the Greater Montréal Transportation system to gather and communicate information about the infrastructure's state through media channels. The transportation community was viewed by respondents as a more effective and open communicator than, for instance, the energy and telecommunication networks. Internal information dissemination within the transportation sector was also more statistically significant in our analysis and more successful (ValiquetteL'Heureux and Therrien 2013).

\section{Methodology}

Our evaluation is based on a qualitative method that allows us to analyze the organizational practices that favor interorganizational resilience, adopted by the members of the network studied. Our main concern was to avoid separating the phenomenon studied from its context. Accordingly, we decided to adopt a semi structured interview technique (Patton 2002). Using this approach, one can discover new perspectives to better understand the phenomenon studied, which may not have been considered during the formulation of the theoretical framework. This methodology thus provides insight into coordination between organizations of the critical infrastructures network by a "sweeping in" process (Dewey 1938). The purpose of this approach resides in its flexibility, because the understanding is gradually consolidated according to the conversations and by addition of points of view on the same phenomenon.

We then identified the organizations in our network that appeared to be most representative of the network studied. The sample comprises 16 organizations in the Greater Montréal transportation network that work in maritime, air, railway, and highway transportation. These organizations represent both the public and private sectors.

The transportation sector is vital maintenance of the quality of life in urban areas. By defining the transportation network of greater Montréal as a sociotechnical system, that is a system composed of interrelated technical and social elements, we can readily consider the members of this infrastructure and its immediate network. The immediate network of our selected organizations is comprised in our analysis. Respondents were asked to define and assess their relationship with the organizations upon which they are directly dependant.

The transportation sector is important because the major players therein are diverse and represent important organizations in the Montréal environment. The Greater Montréal context is distinctive because for most transportation organizations, the managers of the physical infrastructures in the network are public organizations, but the organizations that use these physical infrastructures to carry out their operations are mostly private. In addition, the majority of the entities that secure the network are also public. Organizations targeted by this research are therefore private, public, and parapublic and are involved in the management of the Greater Montréal region transportation network. We define this network of organization as the Greater Montréal transportation system, which represents the main unit of our analysis. We therefore examine the structural strategies of different organizations using system analysis. Within the 16 organizations on which the study focused, we conducted individual interviews with 23 stakeholders. The managers interviewed were not identified to preserve their identity as well as the confidentiality of the information they shared. This methodology allowed us to create pragmatic theoretical concepts, known as grounded theory (Glaser and Strauss 1967). Grounded theory is defined as a theory that "is discovered, developed and provisionally verified through systematic data collection and analysis of data pertaining to that phenomenon. Therefore, data collection, analysis and theory stand in reciprocal relationship with each other" (Strauss and Corbin 1990, p. 23).

Our approach began with open coding of the available data. Specifically, we identified and categorized different variables of the phenomenon studied by examining the data. We thus noted a series of recurrent themes raised during individual interviews, related to the initial hypotheses. We then performed selective analysis of the data. To do so, we identified the constants within each initial category to determine the emerging theory (Gray 2004). We analyzed the relations between the emerging theories and the data available to validate the emerging theories, and identified differences in viewpoints by situating them in their context to define whether these divergences represented marginal exceptions or new emerging theories. After having established the emerging theories and created relations among them, we reached the findings presented in this article.

An approach based on individual interviews yielded a specific vision of the situation. The data obtained appeared rich in examples, but it lacked precision. Although the research was primarily qualitative, we decided to gather some quantitative data to validate certain observations and paint a broader picture of the network examined. We therefore developed a questionnaire to submit to a larger sample of respondents than the number we could interview individually within a reasonable time frame.

To build this questionnaire, we cross tabulated the data obtained during individual interviews with the theoretical bases from the literature. The questions let us validate information obtained during individual interviews and 
permitted us to compare some theories that could not be observed during the interviews. The responses obtained were then weighted by organization. All responding organizations were given equal weight.

We contacted public organizations at the federal, provincial and municipal levels. Given the delicate nature of the subject of interest, the busyness of the vast majority the people we selected, and our several attempts to reach them, either by email or phone, the final response rate of $18.4 \%$ was poor but not unexpected. We obtained results from 36 organizations represented by 86 managers from different departments or divisions who answered to our secure online survey in 2010-our grounded case study is a part of a wider study designed to compare three types of Greater Montreal's critical infrastructure; only the responses from 16 transportation and civil safety partner organizations were kept for this analysis. We believe we met with a sufficient number of actors and compiled responses from enough organizations and their employees to obtain data saturation for the network studied through a replication logic. Accordingly, when the results obtained during the analysis do not allow one to obtain further common threads or to observe marked differences between the subjects, replication has been achieved, and the research hypotheses can be validated (Hlady Rispal 2002).

Our first hypothesis was that although proactive resilience represents a more effective strategy to insure the long-term resilience of a system, few organizations adopt a similar approach. Therefore, the first preoccupation of organizations following crisis would be to restore all activities to their status prior to the event as quickly as possible rather than to maintain a minimum level of service while the organization adapts the structures and models to the event. Our second hypothesis was that some organizations were sharing the management of common problems. We also expected that such collaboration was favored by the collective comprehension that systematic information gathering and sharing made possible. We expected some common action plans resulting from this proactive approach, but we doubted that the majority of such plans would be accompanied by quality measurement indicators. Lastly, we expected that only rarely would organizations enjoy the scientific validation of their common initiatives.

We compiled the responses obtained and analyzed them using the statistical data analysis software SPSS to obtain a more accurate picture of the situation. Cross tabulating these data yielded the findings discussed in this article.

\section{Results}

In this section, the results from our data analysis are presented with reference to the empirical and theoretical background on which our four hypotheses are based. We address first the general agreement antecedents, which refer to cultural and relational "common grounds" that are identified in the literature as favoring coordination. Second, our results regarding the effect of regulations, pressures, and sanctions are put forward. We then move to what our case study enlightens in consideration with the relationship between collaboration and access to resources and finally, power and leadership issues that our survey data explored are presented and discussed.

\subsection{General Agreement: Relational "Common Grounds"}

The relations between members of a same network should be characterized by a common culture, based on the premise that organizations in the same network should share similar values, language, and approach. Relations that rest on mutual agreement about objectives and the roles and responsibilities of each party in the relationship will be more effective. When managing a crisis, those characteristics should improve the effectiveness of concerted actions.

We have evaluated whether overall, the organizations questioned feel that they mutually agree on the objectives of these relations and on the importance of maintaining them. A majority of the respondents agreed with this statement. Among both private $(88 \%)$ and public $(77 \%)$ organizations, respondents agree that relations with close members of their network are based on a common view of the objectives of the relationship. The level of proximity of the various organizations does not seem to have a positive or negative effect on the quality of this relationship. With a few exceptions, the organizations seem to agree on the objectives of their relations regardless of the degree of proximity with other organizations. The mutual agreements that govern relations between organizations in the same network may be formal or informal. Not all organizations conclude explicit agreements to determine the objectives of this relationship or to establish the role and responsibilities of each party. But several stakeholders interviewed think that the formalization of these agreements reduces misunderstandings among the parties concerned. The organizations interviewed whose primary mission is interventionist are more likely to develop formal agreements to regulate responses at a disaster site. Organizations that largely respond to crises often share action frameworks and mutual plans that define the basic roles and responsibilities of the main stakeholders. For example, the Québec provincial government adopted, in cooperation with the main municipalities in the province and the professional associations concerned, a framework for coordination at disaster sites. This cooperative framework was intended to 
guide municipalities and organizations to put in place a system that allowed coordination of responses at disaster sites to ensure an optimal, concerted, and effective response (Québec 2008). This framework has been updated recently, when a new civil safety policy was adopted with the objective of enhancing communities' resilience through better territorial planning, risks communication and mitigation, and coordination and management of disasters (Québec 2014). All organizations that act at disaster sites in Québec must follow the guidelines of this framework. Many respondents also referred to joint response plans that allow organizations to define the role and responsibilities of each actor. These plans set out communication methods between the hierarchical levels of the participating organizations.

Respondents who had a predominantly operational mission had entered into formal agreements mainly with the organizations within its immediate network. Respondents saw some advantages in this relationship concerning the quality of the potential response. Their main priority was to rapidly resume their regular operations following a disaster. The agility and resilience required by crisis situations are fostered by specific elements that reside within the framework of collaboration networks (Camarinha-Matos 2014). Mutual agreement is essential for allowing partner organizations to trust their immediate threat-response network. Resilience can therefore be considered network-wide skill that requires for each network partner to invests its trust.

To reach a mutual agreement on the objectives of the relationship, it is desirable for the stakeholders to have a prior history of good relations. These relations may be imposed by dependence required for the effectiveness of one of the organizations, or by regulation making this relation mandatory. Otherwise, relations can be built on common objectives only if efforts are made to improve the trust among the actors concerned (Ansell and Gash 2008). When no history of sharing exists between the participants in a given network, relations will still be marked by the participants' subjective evaluation, which would probably be characterized more by stereotypes of all kinds (Mandell and Steelman 2003).

The questionnaire therefore asked whether the relationship between organizations and other members of the network rests on a history of good relations. Near $65 \%$ of the respondents agree or agree completely with the statements. Very few respondents $(10 \%)$, the majority of them work at private organizations, think that this relationship is not built on a harmonious history. Respondents from the private sector $(19 \%)$ claim that relations with organizations in their network do not rest on good relations. But there might be a link between the cases where this relationship is not based on a history of good relations and the level of proximity between organizations. The World Economic Forum (2013, p. 20) has pointed out that public sectors in North America and Europe were striving for preferential treatment during crisis and placed priorities on retaining partnerships, whereas within private sectors worldwide prevention of loss of market share and competitiveness draw organizations to search for diversity of supply chains and distrust in governmental actions because of potential negative side effects of government regulation on market profitability.

The quality of the relationship between organizations may rest on shared values, languages, and methods. Gray (1985) says that establishing a common objective during problem solving is greatly facilitated by the sharing of common values between the organizations involved. Inversely, when there is a gap between the values of the various parties, coordinated action may not be smooth. "When stakeholders hold conflicting values and widely differing perspectives on the problem, initial interactions must be designed to promote valid exchange of information and to search common ways to framing the problem" (Gray 1985, p. 925). Most of the respondents (74\%) who completed the questionnaire think that the existence of a shared language facilitates communication between two organizations in the same network. No respondents from the private sector think that relations with different organizations are not facilitated by a shared language. In the public sector, a modest $8 \%$ of respondents think that their relation with other organizations does not rest on a shared vocabulary (Fig. 1). Even if organizations in the same network share a common language, the same is not necessarily true of their methods. Respondents' propensity to agree with the following statement: "Overall, we have approaches and methods in common with the organizations in my network" was much lower than for the shared language statement. Only $9.4 \%$ of respondents agree completely with this assertion. Of those who completed the questionnaire, $19 \%$ claim that they do not have approaches and methods in common with the other organizations in their network (Fig. 1). Organizations in the same network may have a common vocabulary but not necessarily common methods and approaches. Some thus use a common language despite having dissimilar practices.

It is interesting to examine the main incentives that encourage the development of a shared language and procedures. After analyzing the interviews with various stakeholders, we determined that the acquisition of a common language and methods rests on three main pillars. First, the creation of institutional tools of various types allows parties to propose a vocabulary and processes that can be shared with organizations in their network. For example, some organizations developed a video explaining their particular response methods to inform other members 
Fig. 1 Use of shared language, approaches, and methods in public (a) and private (b) organizations
Public organization (a)

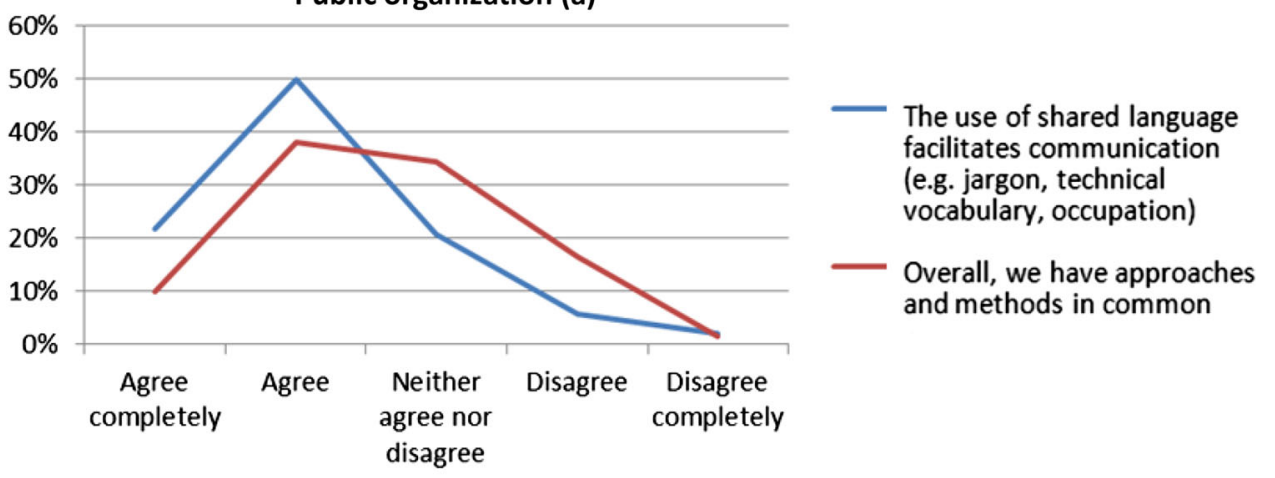

Private organization (b)

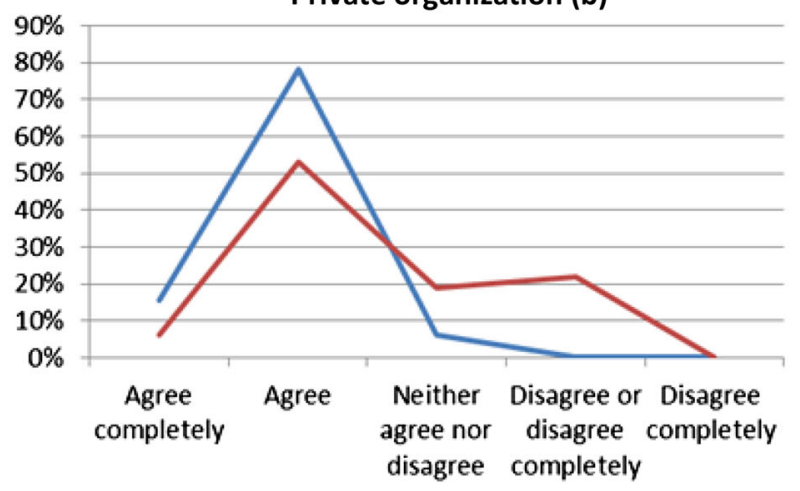

The use of shared language facilitates communication (e.g. jargon, technical vocabulary, occupation)

Overall, we have approaches and methods in common of their network. Some government organizations also favor the production and publication of explanatory documents on good practices in their area of activity and on the related regulations. This approach contributes to the proposal and diffusion of a particular language that organizations want to share.

Second, the creation of formal committees between organizations in the same network, or between representatives of similar departments at different organizations, also favors the acquisition of a shared language and methods. These committees may be strategic or operational. It is possible for organizations to share their particular concerns and propose methods that correspond both to their own objectives and to the needs of other organizations in their network. Such committees would allow organizations to be in contact with particular industries with which they are linked only for specific actions. These working groups allow the parties to exchange necessary information.

So we don't necessarily know the industries in depth, but by being on these platforms, we have a shared language, we listen to their concerns and we can mutually improve our methods to prevent and prepare depending on the risks, etc. (Interview W)

Lastly, organizations that develop and offer training can take pride not only in publicizing the procedures and mechanisms of their operations to participating organizations, but can also develop a precise vocabulary that will be shared by other members of the same network. The respondents supporting this approach think that it will allow them to improve their response and let the organization attenuate the risks to its system arising from interaction involving stakeholders from various spheres. Training is often developed by an organization that hopes that one of the entities of the same network can understand all the facets of a given action. The training proposed by a leader also brings together organizations from the same sector around a particular problem.

Recent literature on extended enterprise systems found that common objectives are achieved in a more efficient fashion when interoperability is present (Mansouri et al. 2011). Such a capacity is closely linked to the extent that each infrastructure constituent effectively works towards that common objective. This shared goal builds network responsiveness, which allows systems, such as transportation systems, to sustain themselves in their ever evolving environments (Mansouri et al. 2011).

\subsection{Regulations, Pressures and Sanctions}

Some relations between members of the same network are governed by legislation or formal rules that make them 
necessary or desirable. Relations between members of the Greater Montréal transportation network are strongly encouraged by the presence of laws and rules. Over $74 \%$ of respondents claim that the effect of the presence of laws or formal rules makes relations necessary or desirable. A total of $75 \%$ of respondents at private organizations agree with this statement, compared with $74 \%$ of respondents in the public sector (Fig. 2). Joint operations between private and public organizations often seem to be structured by legislative and regulatory frameworks.

If the presence of laws and rules dictate a form of collaboration, these relations are not made desirable by the fear of sanctions, be they legal or economic. Barely $26 \%$ of respondents feel that the fear of sanctions supports relations with other members of the network. These fears are more present in the private sector, where $31 \%$ of respondents say they maintain some relations out of fear of sanctions, whereas only $24 \%$ of public organizations do not fear pressures from different sources (Fig. 2). We can therefore posit that laws or rules that govern relations between members of the network are only slightly coercive or not at all, because sanctions have little effect on relations. Further, respondents mentioned potential sanctions for noncompliance with contractual agreements governing their relations more than sanctions stipulated in state laws or regulations.

We also sought to determine whether informal forms of pressure favored relations between stakeholders. Clearly such pressures were present, since $63 \%$ of respondents in the private sector and $61 \%$ of respondents working in public organizations recognize the existence of some form of pressure. This pressure, which may be felt through industry culture, public pressure, or exemplary practices, is experienced equally by private and public organizations. Due to the complex nature of policy objective, and to the growing tendency for public services to be ensured indirectly and by several institutional stakeholders interconnected in multiorganizational networks, one would expect that public organizations would be more subject to collaboration pressure. Interestingly, $8 \%$ of respondents in the public sector disagree completely with this statement, compared with no respondents from private organizations.

\subsection{Access to Resources}

Organizations must consider sharing with other members of a coordinated network worthwhile, because doing so demands time and energy. The stakeholders' participation thus partly depends on their expectations that this collaboration will produce significant results (Ansell and Gash 2008). Incentives to participate are weak when the interested parties can attain their objectives unilaterally or through alternative means. Organizations thus seek relations with other organizations in their network to fill various needs.

Collaboration between organizations can be encouraged by the advantages of this relationship. Access to various resources, be they human, information, or physical, is a considerable incentive for maintaining collaborative relations with other organizations. An organization may require these resources to fulfil its mission. When the resources are essential, the relationship of dependence is critical for the organization.

Four elements in the questionnaire allowed us to paint a general portrait of the effects of access to various resources that favor collaboration between organizations. First, $40 \%$ of respondents think that one of the effects of this relationship is that it allows the organization to access physical resources. The majority of these respondents are in the private sector. Three quarters of the respondents in the private sector report that their relations with different organizations in the network give them access to various physical resources (Fig. 3). Inversely, public organizations seem to be less inclined to seek access to physical resources through their relations with other members of the network: $47 \%$ of public sector respondents disagree with that statement.

Public organizations are not necessarily seeking to increase their organization's financial resources through
Fig. 2 Role of regulations in promoting interorganizational cooperation
The fear of sanctions makes this relation necessary or desirable

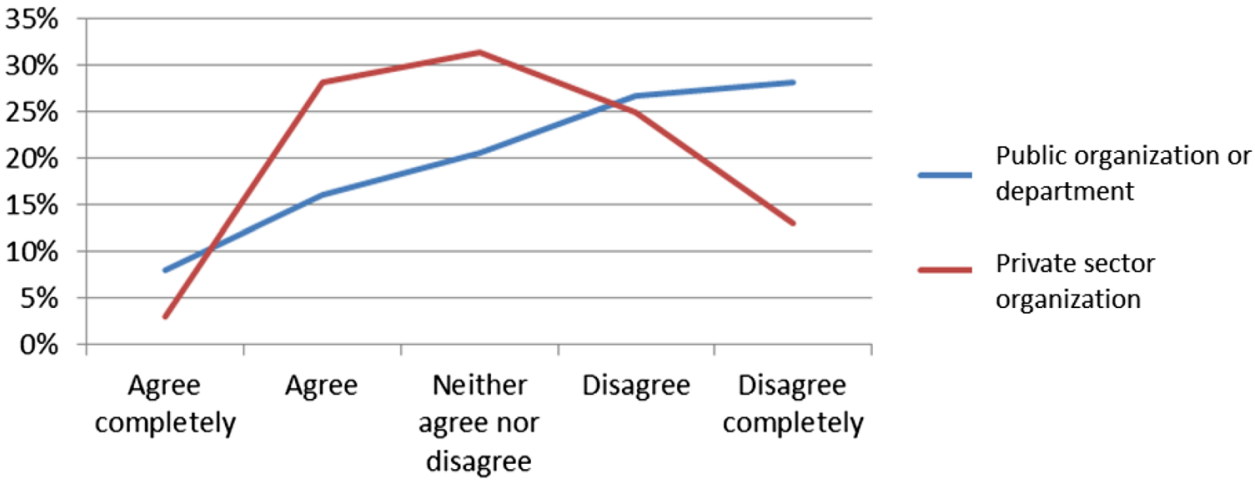


Fig. 3 Access to physical, financial, human, and information resources
Advantages of the relation: increased access to resources

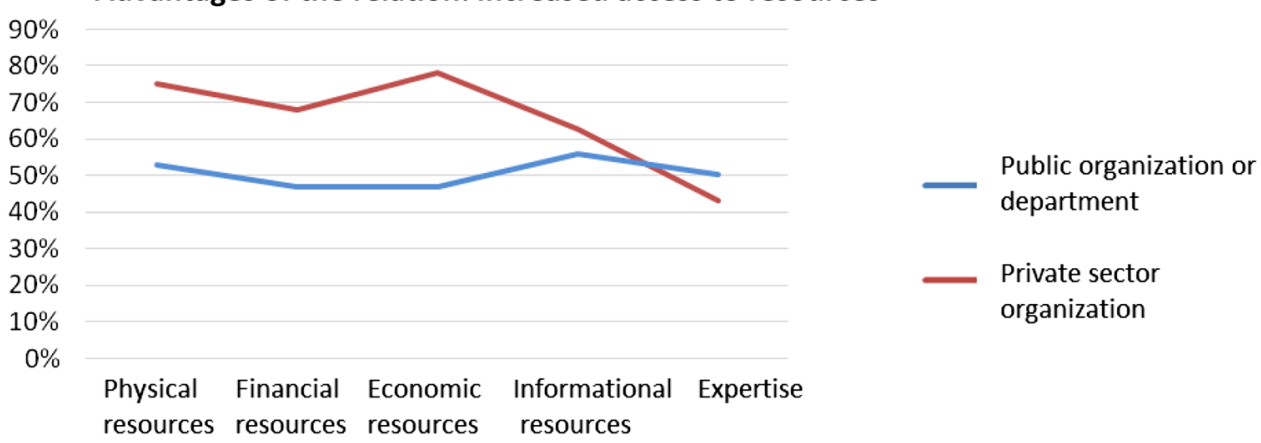

relations with other entities. Slightly more than half of these respondents $(52 \%)$ do not think that one of the effects of their relations is to give them access to different sources of income. In contrast, $69 \%$ of private organizations see a financial advantage in their relations. Overall, $36 \%$ of respondents from all sectors combined think that their organization's relations let them increase their financial resources, whereas $49 \%$ of respondents disagree. We also sought to determine whether the presence of economic advantages such as economies of scale would make relations with other organizations in the network desirable. Once again, this factor encourages more private than public organizations to maintain such relations. Respondents from the private sector $(78 \%)$ note such advantages, whereas less than half $(48 \%)$ of respondents in the public sector share that view (Fig. 3).

Dynamism of organizations is closely related to the extent to which their information-processing abilities are effective in triggering both swift and smooth "reorientation." Such organizational dynamism transforms insights regarding volatility-whether this knowledge is economic and related to demand or to the supply chain-into dynamic restructuring operations that allow institutions to adapt and execute cleverly (Accenture 2012). Since the organizational goals of private organization are dissimilar in many aspects, we anticipated that the efforts in information integration also would differ. Nonetheless, public and private organizations tend to exhibit similar views when it comes to the quest for information resources (Fig. 3). A majority (56\%) of respondents in the public sector agree or agree completely with the following statement: "One of the advantages of this relation is that it increases my organization's information resources (for example, data, statistics)." In the private sector, percentages are slightly higher, but fairly similar, in that $63 \%$ of the respondents also think that one of the effects of their relations is to gain access to different sources of information (Fig. 3).

Lastly, we have examined whether relations between organizations can be encouraged by the search for expertise beyond the organization. Just over half (51\%) of respondents claim that collaboration can let them acquire supplementary expertise, which comes from their collaborators' know-how and practices they have developed or experience they could contribute. It seems that this quest for expertise may be slightly more prevalent among public entities than private organizations. Even if the percentage of respondents that agree with the statement is similar $(50 \%$ in the public sector versus $44 \%$ in the private sector), a larger proportion of respondents in the private sector disagree (38\%) with this statement compared with their counterparts in the public sector (23\%) (Fig. 3).

One can therefore conclude that access to information resources aside, there is a dichotomy between the advantages sought in relations with public and private sector organizations. This finding provides important insight into the reason that organizations forge these relations. Private and public organizations must coordinate their actions during an event that affects critical infrastructures, yet each party is seeking different advantages from these relations.

\subsection{Power and Leadership}

Although stakeholders' participation in an information sharing and coordination process to solve a common problem is generally voluntary, collaboration between organizations may also be imposed by legislation, standards, and formal or informal pressure. Collaboration may also be associated with the relative power of organizations.

Relations of power between organizations in a network have a major impact on the quality of coordination and the involvement of the actors concerned. Imbalances of power between the stakeholders frequently arise when actors participate in a coordinated network. If some stakeholders do not have the capacity, organization, status, or resources required to participate on an equal footing with the other stakeholders, the collaboration process will be subject to manipulation by the strongest actors (Ansell and Gash 2008).

We therefore sought to determine whether relations between respondents were characterized by balanced 
relations of power. We asked respondents whether "this relation rests on egalitarian principles (status, levers of influence, and so on)." Slightly fewer than half the respondents $(49 \%)$ claim that the relations rest on egalitarian principles shared by the members. Surprisingly, this perception of equality between the members of the same network is stronger among private organizations than public entities. Whereas $47 \%$ of respondents at public organizations agree with the statement, $66 \%$ of respondents in the private sector believe that their relations with various organizations are based on egalitarian principles (Fig. 4).

The relative power of organizations is often attributable to their skills and responsibilities. The coexistence of public entities and private organizations within the same network may not have the same influence on their respective partners because the actors do not play the same role (Innes and Booher 1999). Accordingly, respondents perceive executive organizations in a network differently from other members of the network. An entity that has the power to affect organizations in the network will have different power relations than those that must comply with the demands of another institution. The respondents nonetheless expressed the need to reach a consensus during decision making (Fig. 4), and even during the formulation of regulations.

We have close relations with our partners. I think that in most cases, we work in concert with them. I would say there is a mutual influence. For sure, in other cases if something is decided by decree, not everyone's agreement is solicited. In certain cases, it's impossible to have the approval of [...] especially when things are coercive [...] Often we say we really understand the bases, the logic, and why we are obliged to go toward a specific solution. I would say there is a lot of persuasion or understanding [at] work. (Interview $\mathrm{H}$ )

Power plays are particularly evident when an incident has an impact on the continuity of an organization's operations. For instance, economic imperatives propel the most powerful organizations to use the relative power they possess. The respondents feel that the quest for security takes precedence over formal or informal pressures exerted by the other actors.

For government entities in particular, the role of each actor in the network also depends on the territory of the incident. Federal and provincial organizations have similar roles to play depending on the jurisdiction of the event site. For the same event, responsibilities differ if the event occurs on a territory with federal or provincial jurisdiction. A network may comprise actors that have similar roles and responsibilities at different times and that must establish and apply legislation and regulations specifically governing the territory. In such cases, harmonizing regulations facilitates understanding by the other organizations in the network.

The presence of a leader to rally the parties concerned to collaborate and to solve a common problem is a major factor affecting the quality of collaboration, and can reduce the impact of imbalance between the forces at play. Leadership is often perceived as essential to establish and maintain clear rules of the game, to build confidence, facilitate dialogue, and identify the advantages for each of the participants of collaborating in the process (Ansell and Gash 2008). The presence of a leader also facilitates the participation of actors who have relatively lesser weight within the group. The group leader must strike a balance among participants and should allow fair and equitable participation of all concerned.

We determined whether the relations among members of the network were encouraged or supported by the presence of a leader or sponsor. A majority of the respondents ( $56 \%$ ) find that the relation is encouraged by the presence of a leader, be it an individual or organization. More respondents $(56 \%)$ in the public sector agree with the statement. A larger number of respondents (44\%) in the private sector tend to disagree with this statement, versus $20 \%$ of respondents in the public sector (Fig. 5).
Fig. 4 Impact of relations of power between organizations on collaboration of stakeholders
This relation rests on egalitarian principles (e.g. status, levers of influence)

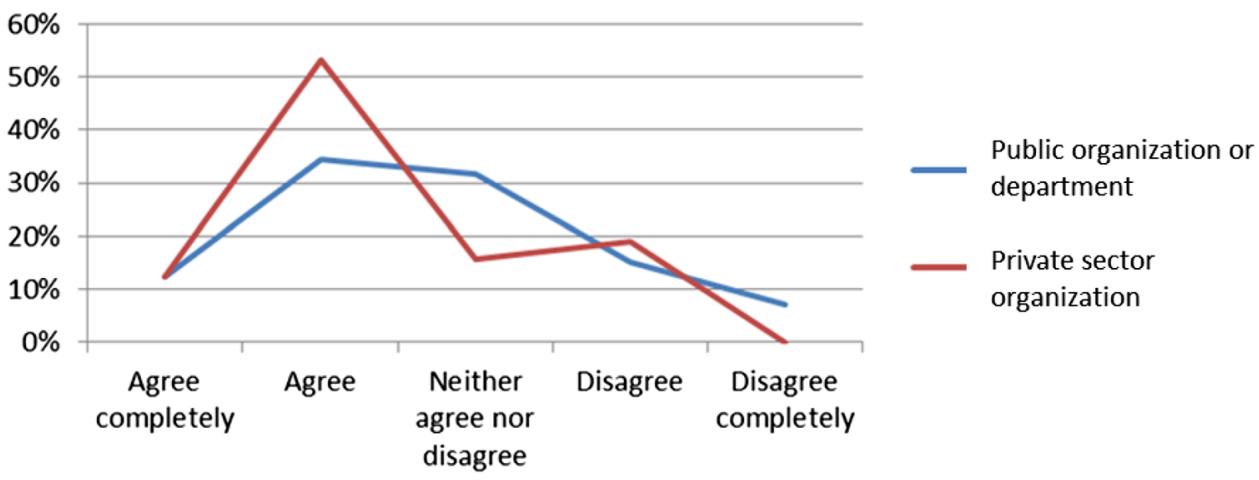


Fig. 5 Leaders or sponsors encourage relations among members of network
Individual or organizational sponsors or leaders encourage or favor this relation

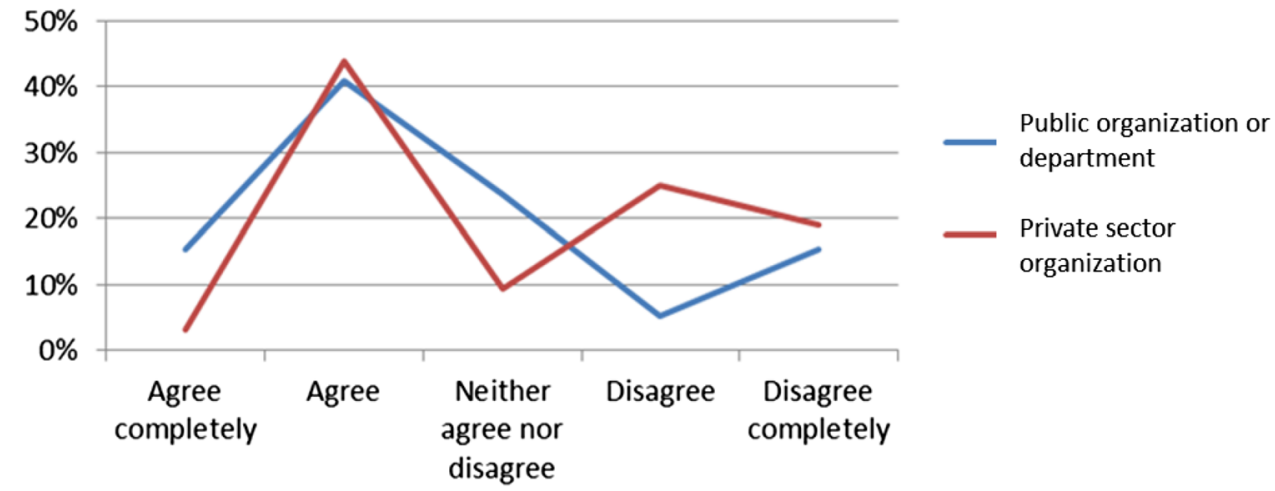

The interviews conducted with various stakeholders from the network studied demonstrated that the presence of a leader always seems desirable, even if one does not actually exist. Stakeholders have expectations of a potential leader: respondents generally consider that this role should be played by one of the public sector actors in the network. Nonetheless, public sector organizations do not necessarily have all the resources required to assume leadership. As mentioned, these organizations seek expertise from their relations with other members of the network. Ultimately, however, they are perceived as the main parties responsible for leading and coordinating the different entities brought together to respond to a situation. When these institutions cannot fully play this role, some of them delegate the responsibility to more qualified individuals or organizations.

We will try to find someone to carry the ball who is used to working in this field. What we tell them is, surround yourself by people. If you have several activities, surround yourself by people who are most skilled to do it because you can't know all the areas, but you're a catalyst. That's the point of view. When people understand that they say 'I don't have all the responsibility on my shoulders. I am responsible for being a catalyst, coordinating, sending and bringing in.' Then they understand. For some it's harder because they're only used to their little box, and if it goes outside the box, it's harder. (Interview W)

When one of the actors takes the leadership role, a ripple effect is often observed.

When you talk to people after the crisis, either everyone took leadership or no one did. When someone becomes the leader and it went well, everyone says they were the leader. And it's true. I think it's true to some extent. "I was the leader until a certain time, after which someone else was, and after that..." (Interview I)

\section{Discussion and Conclusion}

Even if natural and egalitarian collaboration between different members of the same network may be possible, the presence of a leader, whether it is an individual or organization, greatly favors key stakeholders' participation in the collective decision-making process. The presence of a leader confers many advantages such as rebalancing power among the managers present. In fact, the organizations contacted have many expectations about the presence and actions of a leader. This desired leader is often an organization, typically public, that possesses the expertise and powers needed to bring the main stakeholders together and apply measures that favor this collaboration. Such an organization is called the lead organization. "This term refers to the arrangement in which one organization is charged with, or assumes the responsibility for coordinating the activities of all the relevant organizations in the interorganizational networks" (Alexander 1993, p. 337). This definition implies that the lead organization assumes the responsibilities incumbent on all entities that lead a network of organizations. Whereas the lead organization is in charge of coordinating decisions made by the network members, the members are responsible for applying the decisions. This type of structure requires a greater degree of coordination than the ad hoc structures that can be put in place. The model of lead organization thus rests mainly on the structure of the interorganizational system rather than on the mechanics of concerted decision making. Collective decision making is marked primarily by its structure, and therefore by the lead organization. The inability to develop interorganizational relations outside of the structure (for example, because of the lead organization's inability to meet this need) is a potential problem inherent in this model.

Other models of interorganizational structure exist and can be applied to ensure effective collaboration. The simplest structure consists in non administered programs, 
where members are motivated to unify around the problem by simple incentives or sanctions. This approach nonetheless implies that participating organizations must have the power to put structuring action plans into place. The leaders of organization networks may also differ from the lead organization model. For instance, a coordination unit may be formed. Generally, such a unit is differentiated by its autonomy, budget, and resources available to carry out its coordination mission. An individual can also be designated as coordinator, who will act as a catalytic agent of the forces present. But the individual and the coordination unit require autonomy and legitimacy to be able to fulfill their roles and responsibilities.

Coordination at a disaster site in Québec is best fostered by an approach that rallies the main stakeholders around a designated coordinator. At the tactical and operational levels, the main participating organizations must appoint a representative who will coordinate with representatives of the other organizations onsite. This unit, commonly called the on-site emergency operation center, must be coordinated by the representative of the main organization acting on the site. This person is called the site coordinator (Québec 2008).

Structures that formalize responses at a disaster site may also apply and be used by organizations seeking to maintain their activities through a coordinated network. These structures formalize coordination between the members, but can also undermine the flexibility required to ensure a rapid and coordinated response in an uncertain situation, where time is perceived as a determining factor of the quality of the response. Formalization of structures in place to ensure collaboration is necessary only if the network members believe that they require interdependence to attain their own objectives (Gray 1985). Decentralization is important for effective crisis management. The superior level of hierarchy need to support the lower levels of decisions, rather than to manage them (Comfort, Boin et al. 2010, Comfort, Oh et al.2010). Therefore more informal structures can also be put in place, and the identification of a leader can be negotiated by network members. Deference to expertise, rather than to authority, is crucial in order to make timely efforts to cope and recover from threats. This concept can be labelled "deference downward" (Weick and Sutcliffe 2011, p. 77).

Some factors that can be considered and evaluated in only particular contexts may hinder collaboration between various stakeholders in a crisis situation. Actors' response time, trust among the stakeholders, and specific interdependence triggered by the crisis are notable examples. Therefore one cannot determine all the valuables that facilitate or hinder the pooling of various interests at stake during a particular emergency situation. However, pre-existing variables that favor effective collaboration among the different stakeholders in the network can be evaluated.
Diverse prior conditions may favor collaboration among different stakeholders or organizations. A relatively equal balance of power among the different parties, the presence of incentives to favor the participation of the actors concerned, and a history of good relations among the members of the network are the main conditions conducive to effective collaboration (Ansell and Gash 2008; Klijn 2008). We have found that there is generally a history of good relations between the members of the network studied. We also noted that organizations share a common language, but not necessarily methods. Time and effort required to identify common objectives will be reduced accordingly (Gray 1985).

"Collaboration often seemed to depend on achieving a virtuous cycle between communication, trust, commitment, understanding, and outcomes" (Ansell and Gash 2008, p. 16). This research enabled us to examine the factors of trust and understanding. However, as Ansell and Gash emphasize, an intrinsic factor to good collaboration is members' commitment to a common cause. Commitment is thus a highly contextual variable that is influenced by the potential results of the collaboration. We have determined that public sector actors may gain access to particular expertise and information from relations to facilitate their everyday operations. Respondents in the private sector seem to seek relations that will allow them to increase their financial and physical resources. These incentives foster collaboration, but do not guarantee the network members' commitment to share their information, and human or physical resources. These incentives have a greater impact when coordination allows the stakeholders to achieve concrete results.

Lastly, we have observed that the network is characterized by respect and egalitarian principles among the members. This respect ensures the legitimacy of all participants and facilitates the determination of the roles and responsibilities of each party when solving a common problem. "The appreciation of coincident values and dispersion of power among stakeholders enables them to direct their activities toward mutually desirable ends. Once these conditions have been achieved, visible benefits of collaboration can begin to accrue" (Gray 1985, p. 928).

Although our portrait is limited, we can assume that the conditions required to ensure collaboration among the members of the Greater Montréal transportation infrastructure network are present. Pooling the interests of various individuals, organizations, and organizational systems appears to be a process that is applied at times, and future collaboration among members is likely. The various factors evaluated imply that this collaboration would have fairly solid foundations. Thus, the factors that facilitate coordination between members of the same network should be well known by the leader of this network during a crisis situation. 
Acknowledgments Authors would like to thank the anonymous reviewers for their helpful insight. This article was also made possible by the Canadian Social Sciences and Humanities Research Council who provided funding for this research.

Open Access This article is distributed under the terms of the Creative Commons Attribution License which permits any use, distribution, and reproduction in any medium, provided the original author(s) and the source are credited.

\section{References}

Accenture. 2012. Designing dynamic operations: How companies can turn permanent volatility into a permanent competitive advantage. http://www.accenture.com/SiteCollectionDocuments/PDF/Accent ure-Designing-Dynamic-Operations.pdf. Accessed 10 Sept 2014.

Alexander, E.R. 1993. Interorganizational coordination: Theory and practice. Journal of Planning Literature 7(4): 328-343.

Ansell, C., and A. Gash. 2008. Collaborative governance in theory and practice. Journal of Public Administration Research and Theory 18(4): 543-571.

Benson, J.K. 1975. The interorganizational network as a political economy. Administrative Science Quarterly 20(2): 229-249.

Camarinha-Matos, L.M. 2014. Collaborative networks: A mechanism for enterprise agility and resilience. In Enterprise interoperability VI, ed. K. Mertins, F. Bénaben, R. Poler, and J.-P. Bourrières, pp. 3-11. Springer International Publishing.

Comfort, L.K., A. Boin, and C. Demchak. 2010a. Designing resilience: Preparing for extreme events. Pittsburgh, PA: University of Pittsburgh Press.

Comfort, L.K., N. Oh, G. Ertan, and S. Scheinert. 2010b. Designing adaptive systems for disaster mitigation and response: The role of structure. In Designing resilience: Preparing for extreme events, ed. L.K. Comfort, A. Boin, and C. Demchak, 33-62. Pittsburgh: University of Pittsburgh Press.

De Bruijne, M., A. Boin, and M. van Eeten. 2010. Resilience: Exploring the concept and its meanings. In Designing resilience: Peparing for extreme events, ed. L. Comfort, A. Boin, and C. Demchak, 13-32. Pittsburgh: University of Pittsburgh Press.

Dewey, J. 1938. Experience and education. New York: Collier Books. (Collier edn. first published in 1963).

Gilbert, C. 2003. Risk manufactures (La fabrique des risques). Cahiers internationaux de sociologie CXIV: pp. 55-72.

Glaser, B.G., and A.L. Strauss. 1967. The discovery of grounded theory: Strategies for qualitative research. New York: Aldine Publishing Company.

Godbout, F. 2008. Federated states and security: The challenge of the post 11 September 2001 (États fédérés et sécurité : les défi $s$ de l'après 11 septembre 2001). Laboratoire d'étude sur les politiques publiques et la mondialisation.

Gray, B. 1985. Conditions facilitating interorganizational collaboration. Human Relations 38(10): 911-938.

Gray, D.E. 2004. Doing research in the real world. London: Sage.

Hlady Rispal, M. 2002. The case method: Application to management research (La méthode des cas: application à la recherche en gestion). Brussels: Éditions De Boeck Université.

Innes, J.E., and D.E. Booher. 1999. Consensus building and complex adaptive systems: a framework for evaluating collaborative planning. Journal of the American Planning Association 65(4): 412-423.

Johnson, B.L. 1999. The role of adaptive management as an operational approach for resource management agencies. Conservation Ecology 3(2). Article 8.

Klijn, E.H. 2008. Policy and implementation networks: Managing complex interactions. In The Oxford handbook of interorganizational relations, ed. S. Cropper, M. Ebers, C. Huxham, and P. Smith Ring, 118-146. Oxford: Oxford University Press.

Lindsay, J. 2014. The power to react: Review and discussion of Canada's emergency measures legislation. The International Journal of Human Rights 18(2): 159-177.

Lotia, N., and C. Hardy. 2008. Critical perspectives on collaboration. In The Oxford handbook of interorganizational relations, ed. S. Cropper, M. Ebers, C. Huxham, and P. Smith Ring, 366-389. Oxford: Oxford University Press.

Mandell, M.P., and T. Steelman. 2003. Understanding interorganizational innovations. Public Management Review 5(2): 197-224.

Mansouri, M., A. Ganguly, and A. Mostashari. 2011. Evaluating agility in extended enterprise systems: a transportation network case. American Journal of Engineering and Applied Science 4(1): $142-152$.

Patton, D. 2002. Qualitative research and evaluation methods, 3rd edn. Newbury: Sage.

Québec, Gouvernement du. 1994. Determination of anthropogenic stress (Détermination des contraintes de nature anthropique). Direction générale de l'urbanisme et de l'aménagement du territoire du ministère des Affaires municipales du Québec.

Québec, Gouvernement du. 1999. Guide to the establishment and operation of a municipal-industrial joint committee (CMMI) on the risk management of major industrial accidents (Guide pour la création et le fonctionnement d'un comité mixte municipal-industriel (CMMI) sur la gestion des risques d'accidents industriels majeurs). Robert Lapalme du ministère de la Sécurité publique du Québec.

Québec, Gouvernement du. 2008. Disaster site coordination framework in Quebec (Cadre de coordination de site de sinistre au Québec).

Québec, Gouvernement du. 2009. Framework of the government policy to increase the resilience of critical systems in Quebec (Cadre de référence de la démarche gouvernementale visant à accroître la résilience des systèmes essentiels au Québec). Souscomité de l'Organisation de la sécurité civile du Québec (O.S.C.Q.), sur la résilience des systèmes essentiels.

Québec, Gouvernement du. 2014. Québec civil security policy 2014-2024. Towards a more resilient to disasters Quebec society (Politique québécoise de sécurité civile 2014-2024. Vers une société québécoise plus résiliente aux catastrophes).

Schermerhorn, J.R. 1975. Determinants of interorganizational cooperation. Academy of Management Review 18(4): 846-856.

Strauss, A., and J. Corbin. 1990. Basics of qualitative research: Grounded theory procedures and techniques. Newbury Park, CA: Sage.

Therrien, M.-C. 2010. Resilience strategies and critical infrastructure (Stratégies de résilience et infrastructures essentielles). Télescope 16(2): 154-171.

Tremblay, M. 2010. Critical infrastructure: A challenge for the security of states (Les infrastructures essentielles: un défi pour la sécurité des États). Laboratoire d'étude sur les politiques publiques et la mondialisation.

Valiquette L'Heureux, A., and M.-C. Therrien. 2013. Interorganizational dynamics and characteristics of critical infrastructure networks: The study of three critical infrastructures in the greater Montreal area. Journal of Contingencies and Crisis Management 21(4): 211-224.

Weick, K.E., and K.M. Sutcliffe. 2011. Managing the unexpected: Resilient performance in an age of uncertainty, 2nd edn. San Fransisco, CA: Wiley.

Wise, C.R. 2006. Organizing for homeland security after Katrina: Is adaptive management what's missing? Public Administration Review 66(3): 302-318.

World Economic Forum. 2013. Building resilience in supply chains. http://www3.weforum.org/docs/WEF_RRN_MO_BuildingResi lienceSupplyChains_Report_2013.pdf. Accessed 25 Nov 2013. 